\section{THE INFLUENCE OF SOCIAL NETWORKS IN TRAVEL DECISIONS}

\author{
Iulia Elena Varga ${ }^{1}$, Manuela Rozalia Gabor ${ }^{2}$ \\ Received 26. 04. 2021. \\ Sent to review 29. 04. 2021. \\ Accepted 07. 07. 2021.
}

\section{Original Article}

\begin{abstract}
${ }^{1,2}$ George Emil Palade University of Medicine, Pharmacy, Science and Technology of Targu Mure, Romania
\end{abstract}

\section{Corresponding Author: \\ Iulia Elena Varga \\ Email: iulia.varga@umfst.ro}

\section{JEL Classification:}

M31- Marketing, Z31 - Industry Studies

Doi: 10.2478/eoik-2021-0015

UDK 316.472.4:004.738.5]:338.48

\begin{abstract}
Social networks are not the same as they were 10 years ago. Now, in addition to the role of "socialization", their basic role, marketing has also intervened. Marketing can be defined as the art of identifying and satisfying customer needs while producing profit. Nowadays, through social media marketing, a company can promote itself or present products and services very easily, while being able to target exactly the desired people, which translates into making more profit. Our paper provides arguments on the influence of social media in travel decisions, and it's based on a study of consumer behaviour in this field. The study began from our interest in the way social networks influence our personal decision to travel, to visit a certain area or a certain landmark, so we wanted to find out more information about how this "hypnosis" works. The main hypothesis of the study was that people are influenced by social networks in their travel decisions and according to the results, the hypothesis was confirmed. $91.35 \%$ of the total participants in the study were tempted to travel because of a photo seen on a social network, therefore, a good social marketing campaign could really make a difference in travel decisions.
\end{abstract}

Keywords: Marketing research, Consumer behaviour, Social networks, Tourism

\section{INTRODUCTION}

Since the rise of the Internet in the early 1990s, the world's networked population has grown from millions to billions. Over the same period, social media have become a fact of life for civil society worldwide, involving many actors - regular citizens, activists, nongovernmental organizations, telecommunications firms, software providers, governments etc (Shirky, 2011). 
Figure 1. Key figures of the digital world - October 2020.

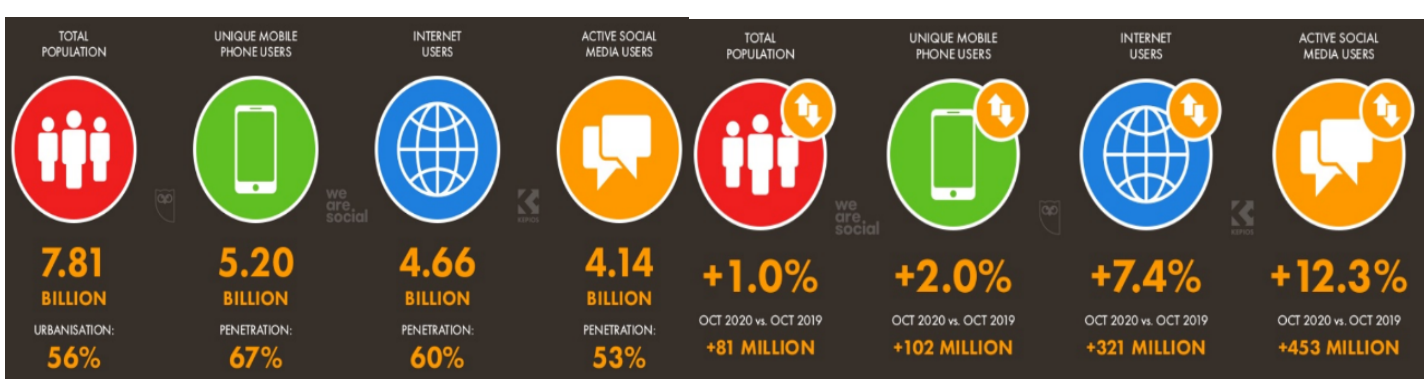

Source: Digital 2020 October Global Statshot Report

(https://datareportal.com/reports/digital-2020-october-global-statshot).

According to Hootsuite and We Are Social, in October 2020, the world's population was 7.81 billion people, of which 4.66 billion are internet users (the penetration rate being of $60 \%$ ) and 4.14 billion are social network users (53\% of the population). Compared to 2019 , this means a $1 \%$ increase of the total population, a $7.4 \%$ increase of the number of internet users and a $12,3 \%$ increase of social network users. Social media has become a vital part of everyday life for people around the world, and it is also increasingly used by companies as part of marketing, customer service, research, and development strategies (Varga, 2018). Regarding the perspectives on how internet users relate with social media, things are extremely interesting, the most important data being presented in the Digital 2020 Global Report:

Figure 2. Social media behaviour - October 2020.

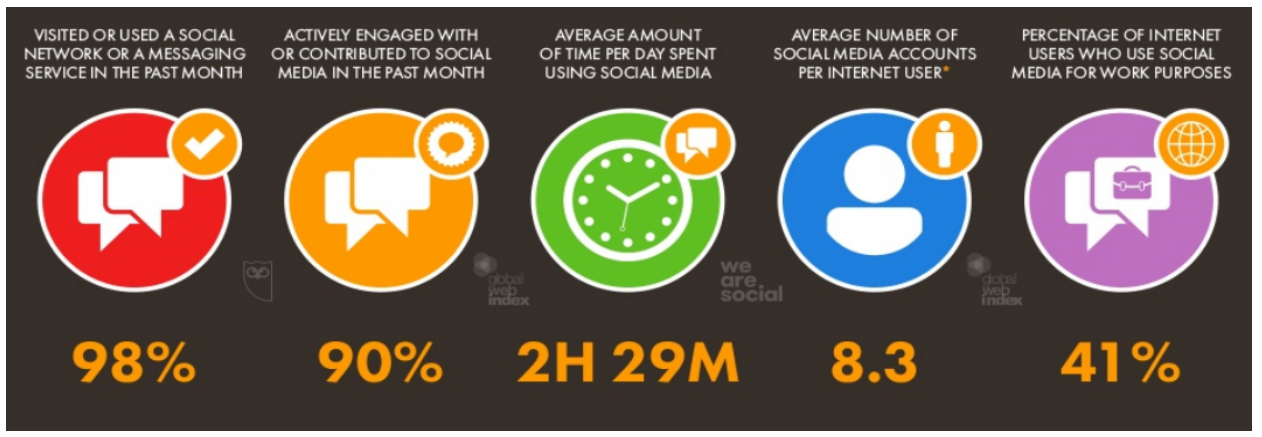

Source: Digital 2020 October Global Statshot Report

(https://datareportal.com/reports/digital-2020-october-global-statshot).

As we can observe in Figure 2, 98\% of internet users visited or used a social media network in the past month, the average amount of time per day spent using social media was of two hours and a half and only $41 \%$ of internet users, used social media for work purposes. The social media is an important aspect of tourism industry. It provides to the tour operators a multitude of tools through which they can influence consumer perceptions, tools that are easy to use, have low costs but can at the same time, if not properly used to negatively affect consumers (Sârbu, Alecu, Dina, 2018).

Social media provides information for travelers on the destination and the touristic enterprises located at such destination and contains the opinions and experience of people who have traveled there, affecting the decision-making process. On the other hand, tourism enterprises are able to reach the ideas and opinions of the travelers on their experience via social media and thus understand their customers better and gain a competitive edge in the market (Erol, Ülkü, 2019). 


\section{SOCIAL MEDIA' PARTICULARITIES FOR ROMANIAN MARKET}

Nowadays, the terms "tourism" and "tourist" can be appreciated as international terms and are used, in most modern languages, in the designation of travel and, of course, people traveling for tourism purposes. We can define the tourist as a person who moves to a place located outside the usual residence for a period of less than 12 months, the main reasons for travel being other than some paid activity in the visited place.The evolution of tourism in Romania is characterized by a growing trend due to the influence of economic, demographic, political and social factors, of which we mention the desire of people to visit certain touristic areas, to know local customs and the technical progress of the infrastructure.

Figure 3. The evolution of tourists arrivals in Romania between 2011 and 2019.

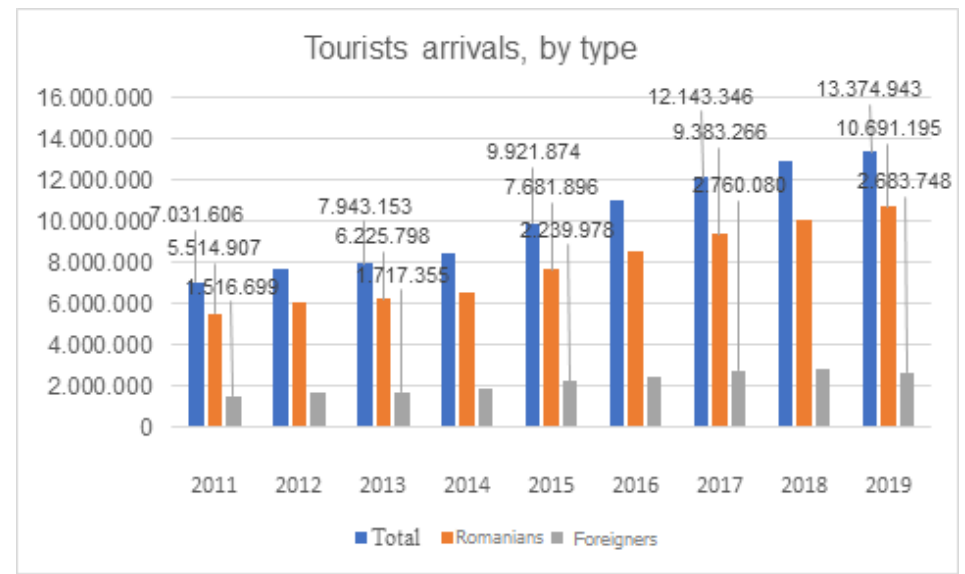

Source: based on INSSE information (https://insse.ro).

According to Figure 3, during the entire analyzed period, there was an increase of $8.70 \%$ of Romanian tourists arriving in the accommodation units and an increase of $7.58 \%$ of foreign tourists.Social media are online platforms that facilitate global collaboration and sharing amongst users. It includes websites and other online tools (called social networks) that enable people and organizations to get, create, and share content by interacting with others about topics of common interest (Roberts, Callahan, O'Leary, 2017). Safko and Brake describe social media as "activities, practices and behaviours among communities of people who gather online to share information, knowledge, and opinions using conversational media".

Figure 4. Most used social media platforms worldwide.

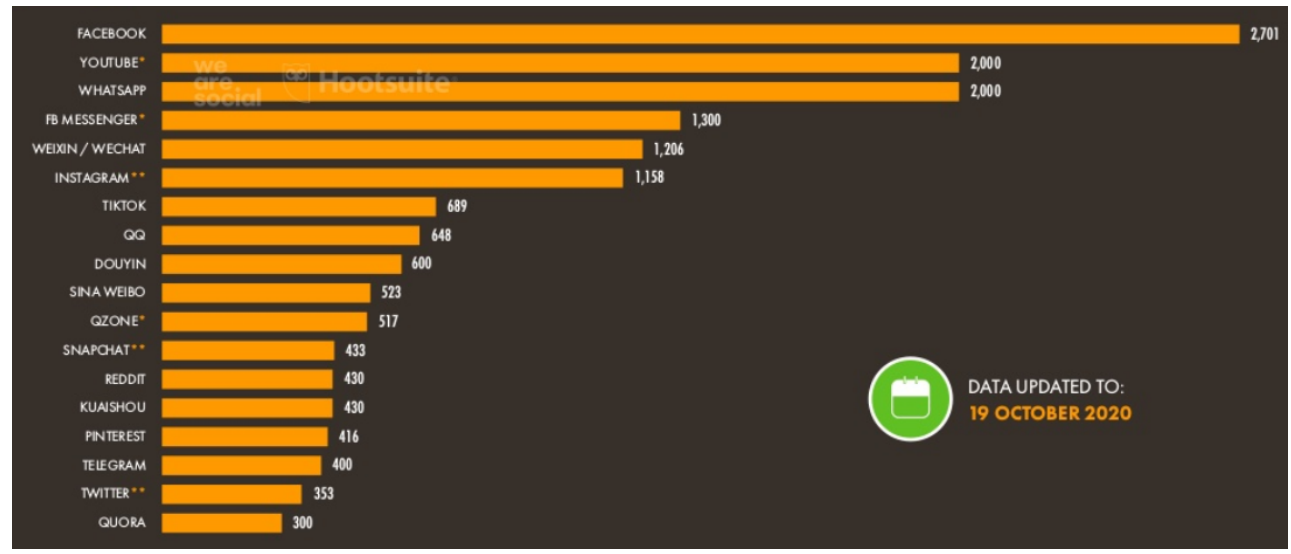

Source: Digital 2020 October Global Statshot Report

(https://datareportal.com/reports/digital-2020-october-global-statshot). 
Among the most popular social networks worldwide are Facebook, with the largest number of users, Youtube and Instagram. Almost all these networks saw strong audience growth in the last months, but Instagram and Snapchat had the biggest increases. In Romania, Facebook and Instagram are the most frequently used social networks.

Figure 5. Number of Facebook users in Romania between January 2011 and January 2020.

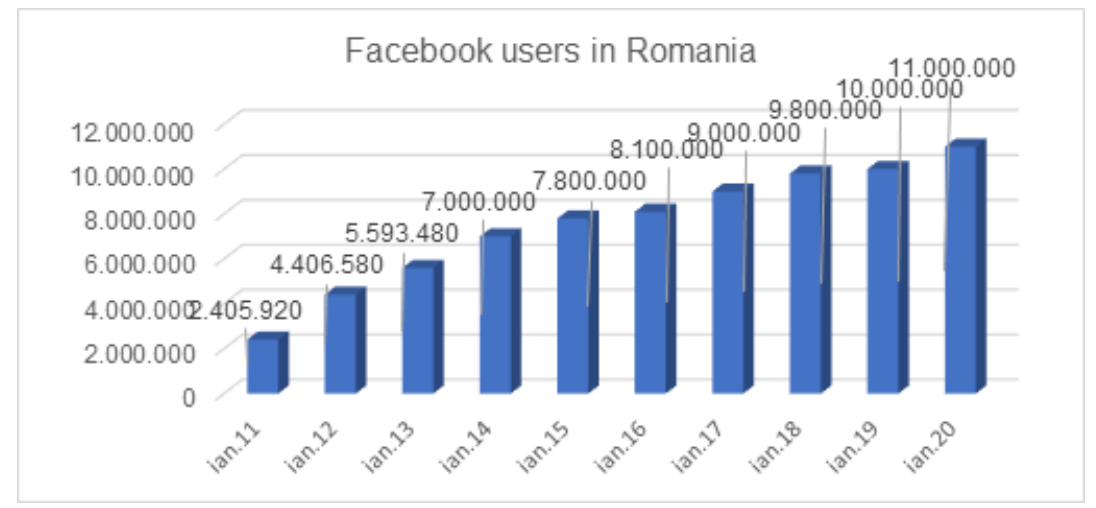

Source: based on information from (http://www.facebrands.ro) and (https://www.zelist.ro).

According to Figure 5, the number of Romanian Facebook users increased considerably from year to year, the largest increase being from January 2011 to January 2012, when their number almost doubled. Facebook is a social network that provides the opportunity for people to share photos, information, videos and more. Users can decide who can see their posts, whether their profile is private or public, and many other settings that the user can make based on their own decisions. From the very beginning, when Mark Zuckerberg launched the social network in 2004, Facebook was a success among Harvard University students. Nowadays, Facebook is the biggest social network worldwide, with 2,8 billion monthly active users (www.statista.com). Instagram is a social network where people can share with friends and their followers their daily lives, through photos or videos. The first photo posted on Instagram was in July 2010 by founders Kevin Systrom and Mike Krieger, and it was launched to the public in October 2010 (www.instagram.com). Worldwide, the number of Instagram users in October 2020, was around 1.1 billion and over 60\% of them are aged between 18 and 34 years old (www.statista.com). In an Instagram post, users can also use "hashtag" - one or more words that enclose a photo or video. For example, for a photo with an individual by the beach, we can use the following hashtags: \# sea \# seaside \# holiday \#sun \# costinesti. Instagram users who will search on Instagram "\# holiday, will be able to see only photos and videos that have the description of the hashtag. Likewise, the user can attach the location where the photo / video posted was taken, and the users who type that location will only see photos / videos that have the location of the posts attached. 
Figure 6. The evolution of Instagram users in Romania between 2013 and 2020.

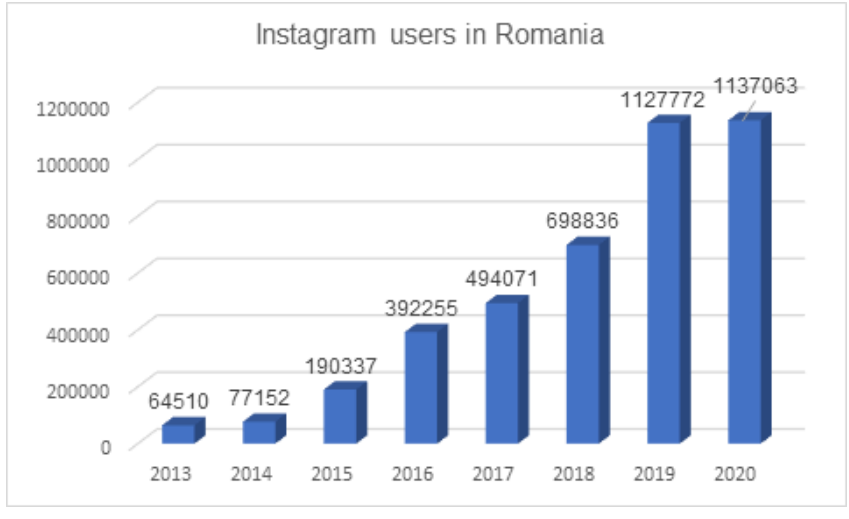

Source: based on information from (https://www.zelist.ro).

Analyzing the data presented above, we can observe that it was a massive increase in Instagram users in Romania. The biggest increase was between 2014-2015, when the number of Instagram users increased from 77.152 users to 190.337 users, an increase of $146.70 \%$ in 2015 compared to 2014. From 2019 to 2020, there was only a slight increase, which suggests a cap on the number of Instagram users.

\section{THE RELATION BETWEEN SOCIAL NETWORKS AND TOURISM}

Tourism industry relies mainly on information and communication technologies for promotional activities, sales or development of customer relationship. When an individual wants to decide on a travel destination, the most important information comes from friends and online sources. Based on travel agency's needs, social networks use advanced technology to create a personalized offer, taking into consideration previous searches made by a user on the Internet about certain areas or landmarks. Nowadays, tourists have more confidence in the opinions of other people who have traveled to a certain country, area, only using social networks. Social networks are becoming more popular, with more users from day to day, so consumers can influence more and more consumers about their own opinions and experiences.

Technological advancement has contributed to fundamental changes in the tourism industry and helped people to make a travel decision. An online survey of 4.600 respondents was conducted in October 2012 in the US, Europe and Asia Pacific (as targeted people were people who traveled for free in the last 12 months or intended to do so in the next 12 months). This study showed that social networks have a great influence on a person's travel decision, as $44 \%$ of respondents said that internet reviews posted by bloggers (tourism influencers) helped them decide on their travel destination. 27\% of respondents said they were helped in their decision by Facebook, 24\% by YouTube and 22\% by Pinterest (Živković, Gajić, Brdar, 2014). The year 2020 was a significant one in social media. The pandemic pushed more people to spend time online and find more ways to engage with each other. When examining B2B advertising, social media advertising was used by $83 \%$ of marketers and ranked second in success $(29 \%)$ behind search engine marketing (33\%). (https://sproutsocial.com/insights/social-media-statistics/). Advertising is very important for any company, especially for a travel agency. It aims to promote a product or service and to increase sales. In this context, any travel agency must be present on social networks, where the public is, especially on Facebook and Instagram. AIDA model shows that the effectiveness of any advertising depends upon the extent to which the advertising message has been received and accepted by the audience (Gupta, Singh, Sinha, 2017). Starting from its main principles - capture the attention of the potential customer, rise the interest in the object of sale, provoke the desire to buy and action the sale, we made an analysis on a travel agency post on a social network, to see if it respects them. 
Figure 7. Travel agency post regarding a holiday offer in Greece.

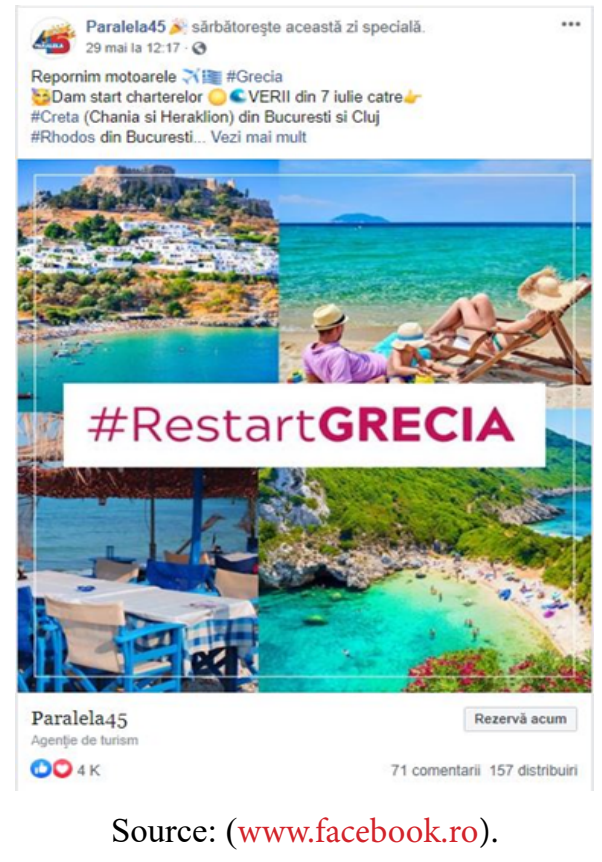

Parallel 45 presents its offer with a promising start, "Restart engines", following the COVID-19 pandemic. In the first phase, the capture of attention was successful. Why do I say this? Because the post has some beautiful images and a description. The images reflect some grate landscapes, a family relaxing, and a restaurant on the beach, so there are great chances for a user who sees the post to stop "browsing" and view the offer. Rising the interest - the holiday season is approaching, people are looking for an offer and we can see this from the number of appreciations, about 4.000, the number of distributions, 157, and 71 comments. It should be noted that the impact of the poste was much greater than the data presented. Why? Because the virtual friends of the people who appreciated the photo, probably saw in "News" that person X appreciated, commented, or shared the post published by Parallel 45. Regarding the desire to buy and the actual purchase, we can assume that from the large number of people who interacted with the post, at least a few were interested. When it comes to travel and decision making, we can remember the saying "A picture is worth 1,000 words". Instagram is based on images, and a really good photo, which conveys a state, if it's accompanied by a short story, can make the difference between going over it without mattering and making a travel decision. According to the article entitled "Instagram Must Be in the Top of Social Networks in Tourism" viewed on https://www.turismmarket.com, $65 \%$ of people learn visually: it is easier to retain images and learn through them, $70 \%$ of the receptor sensors are in the eye and $90 \%$ of the information transmitted to the brain is visual. It is not a novelty that social networks have "entered" our daily lives. We wake up, many of us check phones, access Facebook, Instagram and other social networks, depending on the individual, as if we did not do this action before we fall asleep. People started using these social networks in as many ways as possible. For example, on Facebook, before the appearance of the "Marketplace" sales function, people created groups for the purpose of selling. For example, at local level (Mureș county), we have many groups, such as: "Buy Sell Mureș”, "Mureș Market”, “Announcements Mureș”, each of them having thousands of members. Like the sales groups, there are also tourism groups, where people who are passionate about travel or who simply want to know more details about their country, can register. For example, in Romania we have: "Holidays in Romania", "Holidays do it yourself", "We travel in Romania", "Holiday ideas" and many others. "Holidays in Romania" counts 207.000 members in the present, and they all can see recommendations, comments and appreciations for various areas / tourist attractions posted by the group. 
Figure 8. A Facebook post in the group "Holidays in Romania".

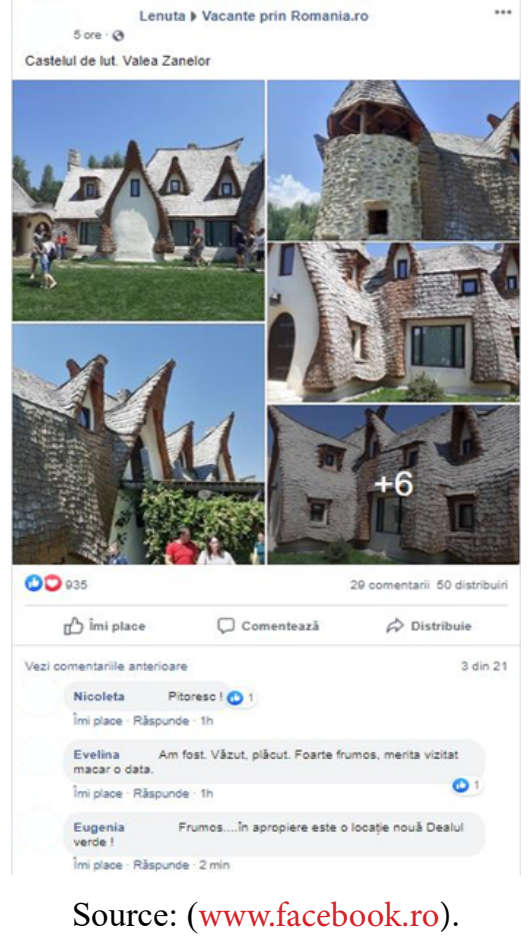

As we can see in Figure 8, a member of the group posted some photos from his vacation, specifying the name of the tourist attraction, and there were 29 comments, 935 appreciations and 50 distributions at the time of the screenshot. Other people ask for ideas and recommendations on a holiday group on Facebook and each request has a large number of answers.

\section{METHODOLOGY}

We conducted a quantitative research based on a questionnaire with 18 questions comprising several aspects on the relationship of social media and tourism. 6 of these questions refer to socialdemographic aspects of the respondents. We used both closed and semi-open questions, such as: Do you check social networks before making a travel decision?, Do you specify the location in social media posts?, Are you using hashtag when posting a photo on vacation?, Gender, or Marital status. To verify our hypothesis "People are influenced by social networks in their travel decisions", we targeted social media users, so we distributed the questionnaire to family, friends, friends of friends, virtual friends on social networks, travel groups on Facebook. The questionnaire was made using Google Forms, so its distribution was completely online and the aim was to reach a number of at least 100 respondents. We collected the data between 21.06.2020-01.07.2020 and we analyzed them with SPSS and Microsoft Excel.

\subsection{SAMPLE PRESENTATION}

Starting from the idea that the results can be extrapolated, we collected data from 104 respondents to obtain some key aspects regarding the influence of social media in travel decisions. Here are the results on social demographic variables of the sample: 
Figure 9. Age and gender of the respondents.

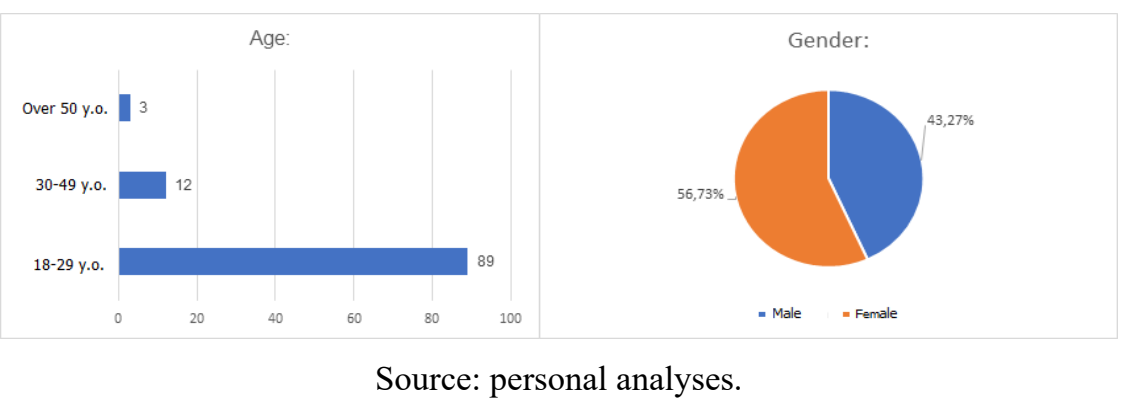

As we can observe from the figure above, most of the respondents are aged between 18-29 years old, more precisely, $85.58 \%$ of the total (89 persons). $11.54 \%$ have between $30-49$ years old, and $2.88 \%$ are over 50 . The rather large differences between the age categories can be, from our point of view, explained by the fact that young people are generally more active in social networks and being a self-sampling, they were more willing to participate in our study. Regarding the gender, women are more present on social networks than men, with $56.73 \%$ of the respondents, but the differences are not verry big.

Figure 10. Occupation and completed studies.

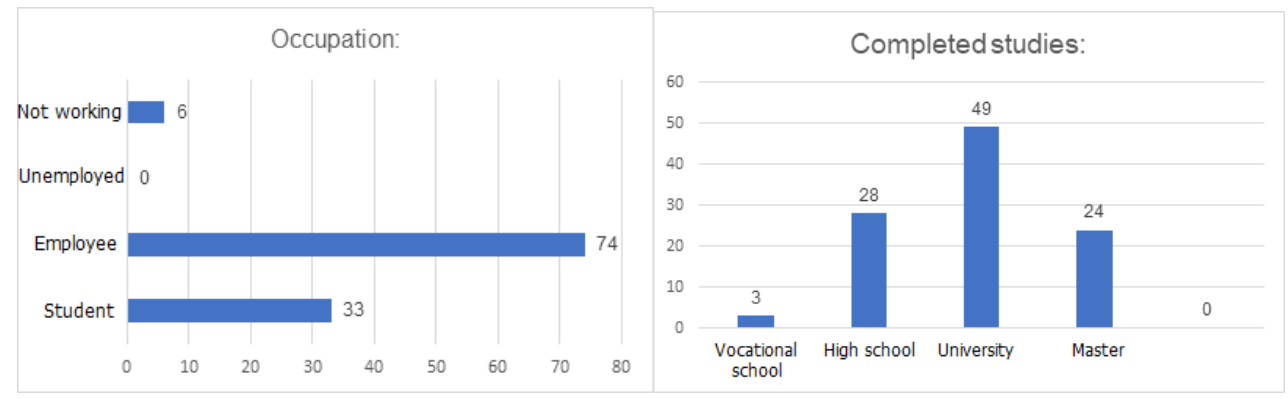

Source: personal analyses.

Analyzing the occupation, we noticed that over $65 \%$ of the respondents are employed and almost $30 \%$ students, but an encouraging fact regarding the situation in Romania is that none of the respondents are unemployed. In relation with these figures, most of the respondent have University studies and $26,92 \%$ completed high school.

Figure 11. Marital status and living area.

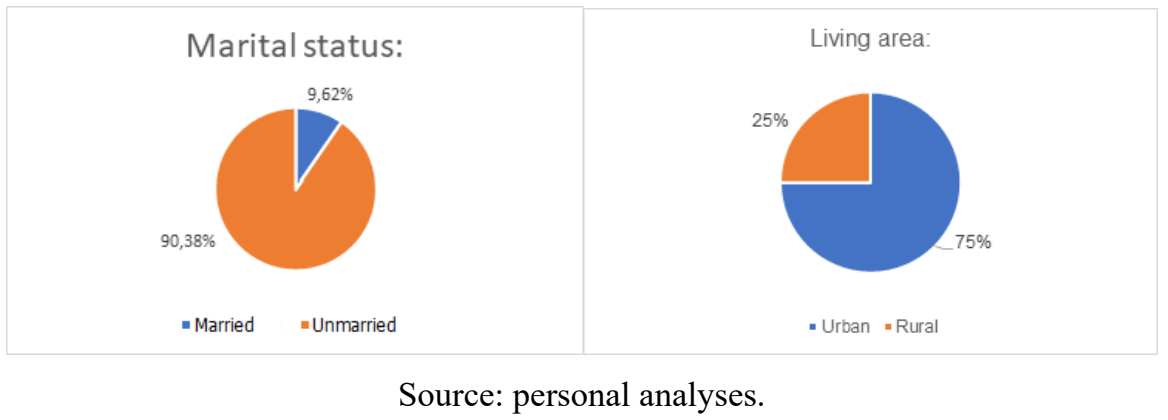

A verry interesting aspect regarding the social media user profile is related to marital status. As we can see in Figure 11, 90.38\% of the respondents are unmarried, while only $9.62 \%$ are married, which may be justified by the greater need for socialization in the case of unmarried people. It is also observed from the figure, that most of the respondents are from urban area. 


\section{RESULTS}

In this section we will present a synthesis of the main aspects that emerged from the study. These are meant to give us an idea on the consumer behavior and the impact that social networks have on our lives.

Figure 12. Average time spent on social media

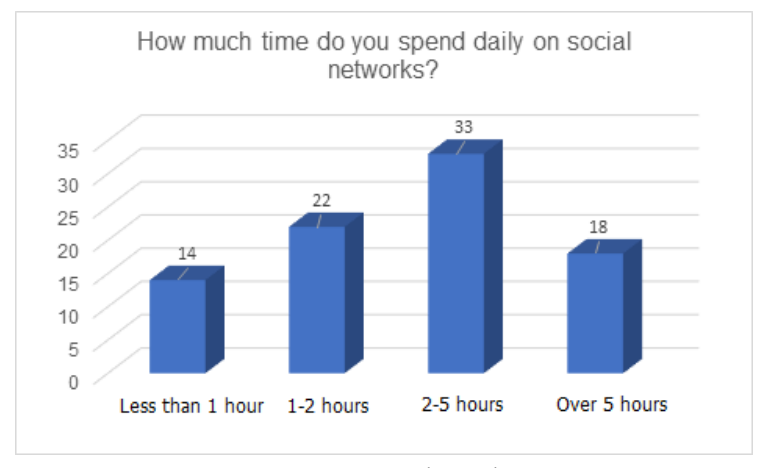

Source: personal analyses.

Most of the respondents (37.93\%) spend daily between 2 and 5 hours on social networks, followed by those who spend between 1 and 2 hours (25.29\%). The worrying aspect is given by the $20.69 \%$ of the respondents who spend more than 5 hours, daily, on social networks, but, looking from the point of view of our topic, these people accumulate the most information and have the higher "risk" of being influenced comparative to those who spend less than 1 hour a day on social media.

Figure 13. Follow travel agencies on social media.

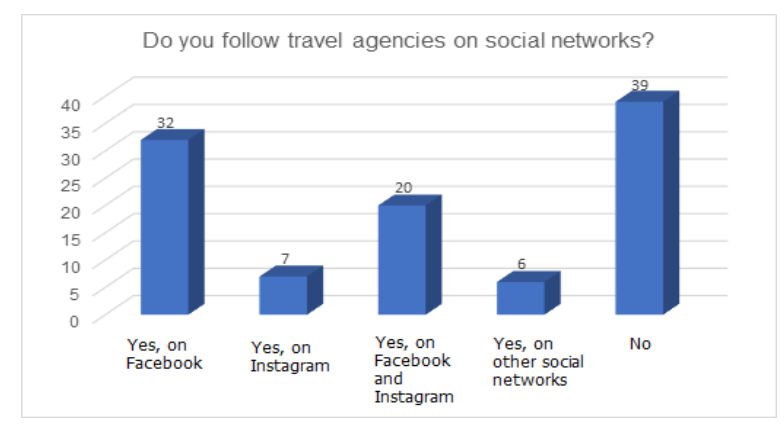

Source: personal analyses.

Another key aspect of the study is related to whether the respondents are following travel agencies on social platforms or not. Figure 13 shows that even if more than $60 \%$ of the respondents are doing these, there is also a percentage of $37,50 \%$ who doesn't. We can also see the respondents tendency to follow travel agencies on Facebook and not on Instagram, fact that can be explained by Facebook groups, where people can sign up and share holiday photos, opinions, ideas, conclusions, great deals and more. 
Figure 14. Influence of a photo seen on social media.

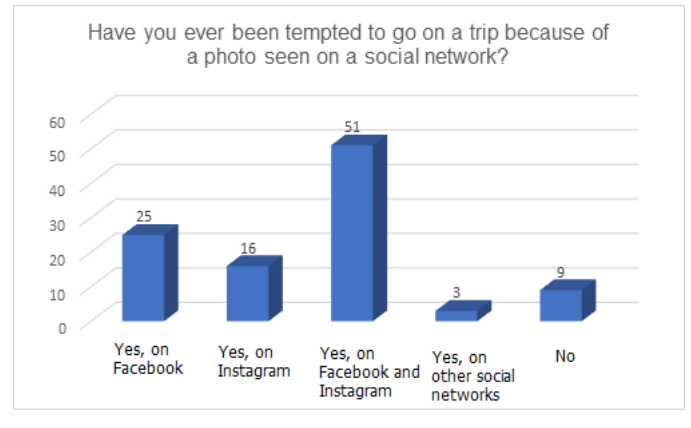

Source: personal analyses.

$91.35 \%$ of the total participants in the study answered that they were tempted to travel because of a photo seen on a social network, while only $8.65 \%$ answered that this did not happen to them. The difference between the responses is more than edifying and again, the preference for Facebook is visible. We had another similar question in our study, if the respondents visited a tourist area after viewing a photo posted on a social network and $82.69 \%$ of the respondents said yes, and only $17.31 \%$ said no. It turns out that there is a difference of $8.66 \%$ of respondents who managed to stop the temptation to travel as a result of viewing a post on social networks.

Figure 15. Follow of pages/accounts/travel groups on social media.

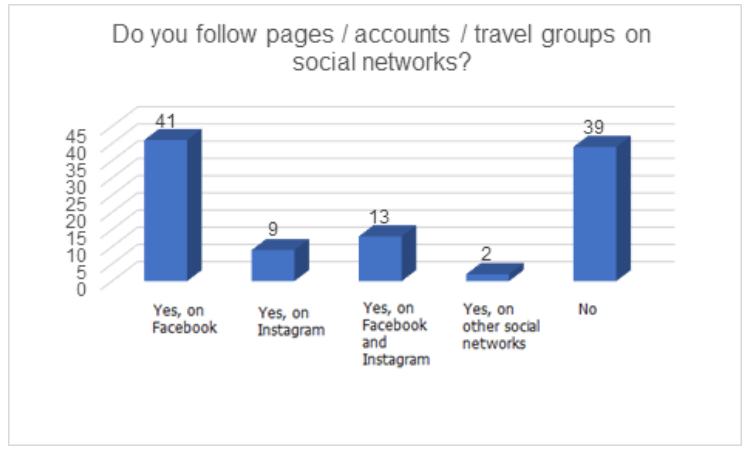

Source: personal analyses.

According to the figure above, $39.42 \%$ of the respondents follow pages / accounts / groups on Facebook, while only $8.65 \%$ follow on Instagram and $1.92 \%$ on other social networks.

Figure 16. Temptation versus action.

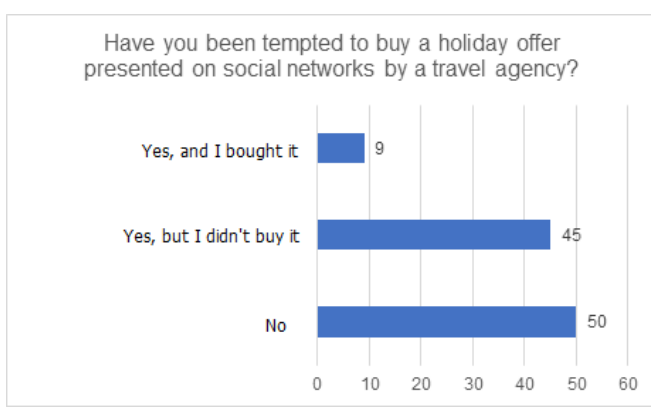

Source: personal analyses.

A very interesting question found in the study was "Have you been tempted to buy a holiday offer presented on social networks by a travel agency?" and the answers leave room for interpretation. 
The first thing we notice is that $48.08 \%$ of the respondents were not even tempted to buy from the tourist offers presented on social networks. Then, $43.27 \%$ say they were tempted to purchase but did not complete this action. Although we do not know the reasons that prevented the purchase, it is certain that travel agencies that promote themselves or some offers on social networks, should act and identify the "problem / problems" that discourage people tempted by the offers to buy them. Out of all the interviewed persons, there are also respondents who answered that they were influenced to purchase an offer presented on social networks and they also purchased it, but their number is pretty low (only $8.65 \%$ of the total).

Figure 17. Posting holiday photos on social media.

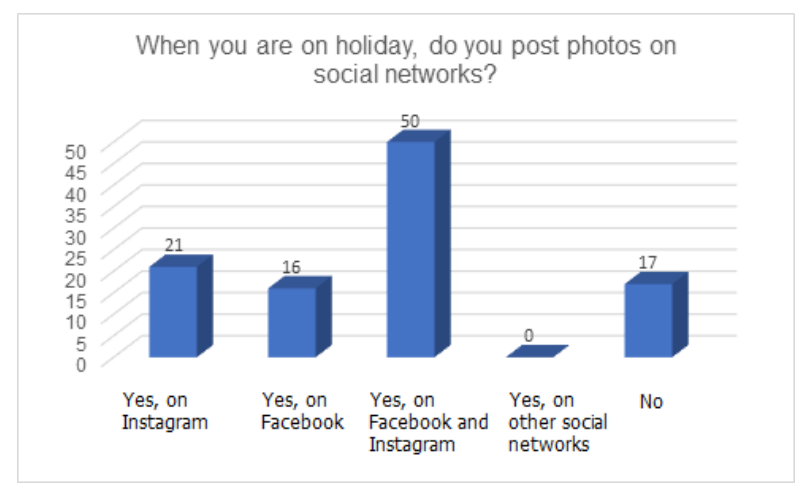

Source: personal analyses.

Out of the 104 people surveyed, $83.65 \%$ post holiday photos on social networks, most of them opting for both platforms (Facebook and Instagram). However, figures show a certain preference for Instagram when it comes to posting images.

Figure 18. Consulting social media in decision process.

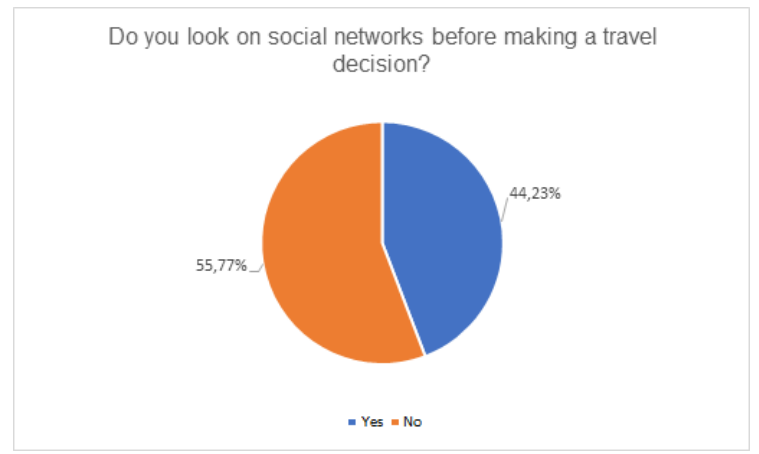

Source: personal analyses.

$55.77 \%$ of the participants of the study do not consult social networks before making a travel decision, and $44.23 \%$ they do. From our perspective, it could be useful to consult social networks before going on a vacation, especially from the point of view of choosing an accommodation, to avoid not too pleasant "surprises", such as poor hygiene, broken electrical equipment and so on. You can search on a tourist group the name of the unit and follow the comments and the reviews received, or you can simply ask a question and the answers received could help you make a better decision. Also, from social networks, we can find more information related to the tourist objectives located in the surroundings of the chosen location, restaurants and many other useful information. 
Figure 19. Location and hashtag options.

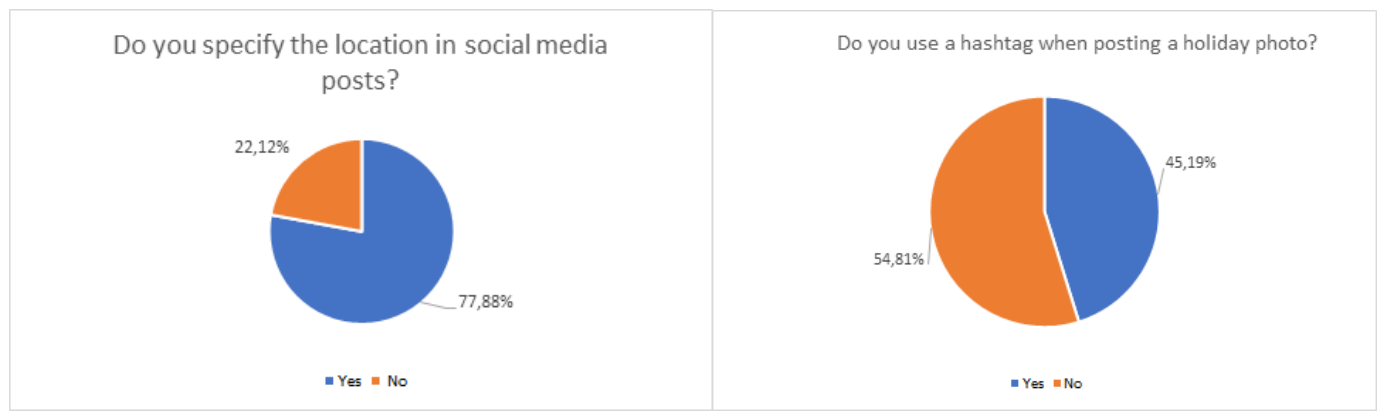

Source: personal analyses.

The latest results of the study presented, refer to location and hashtag, two of the options we have on social platforms and that can contribute to the growth of tourism in a certain area. $77.88 \%$ of the total respondents specify the location in their social media posts, while only $22,12 \%$ doesn't. Specifying the location of a photo posted on a social network is very important, because a person can more easily identify the place where a photo was taken and there is the possibility, if it caught the person's attention, to visit that place. This increases the number of tourists in that area and supports the economy. Regarding the hashtag, the number of those who do not use this option is higher than of those who use it, $54,81 \%$ versus $45,19 \%$. Using this option is also good for tourism, because many holiday photos, from different parts of the world, are posted on social networks, different tourist attractions, tourist areas, tourist destinations, and with a simple hashtag, we can embed all photos in one certain hashtag, making searches much easier. We've also used the chi square test to see if there are certain statistical correlations between various variables and the conclusions were as follows:

- the hypothesis "There are no significant differences between age and the temptation to go on a trip because of a photo seen on a social network" was rejected, the value of chi square $(36,685)$ being higher than the likelihood ratio $(26.12)$;

- the hypothesis "There are no significant differences between age and posting holiday photos on social networks" was rejected, the value of chi square $(17,068)$ being higher than the likelihood ratio $(16,811)$;

- the hypothesis "There are no significant differences between marital status and the use of hashtags" was rejected, the value of chi square $(2,835)$ being higher than the likelihood ratio $(2,705)$. 


\section{CONCLUSIONS}

Statistics show that people are each day more and more present in the online environment and on social media, share their vacations, opinions, ideas and criticisms through them, and in response, social networks have "adapted" and they give us what we are interested in, observing our past actions or coming with new and more attractive facilities. Online platforms, such as social networks, blogs, video, audio, or knowledge sharing platforms, are considered as marketing tools because they offer both the possibility to promote products and services and also to obtain precious information about the needs and behaviour of consumers (Sârbu, Alecu, Dina, 2018). Today, social media has a significant impact over the tourism industry, most of the time, the user generated content is more important than any official information, so it's crucial for any company to develop a solid and effective social media strategy (Nikjoo, Ketabi, 2015). According to our study, $38 \%$ of the respondents spend between 2 and 5 hours per day on social networks, while $20 \%$ of them, spend more than 5 hours, and only $37 \%$ of the respondents say they do not follow travel agencies on social platforms. From our point of view, this is a huge marketing opportunity for travel agencies. Social networks facilitate the development of a closer relationship with customers, who can then, get involved in promoting tourist destinations or holiday offers. In Romania, Facebook and Instagram are the most popular social networks, and regarding the tourism, $91.35 \%$ of the respondents said that they were tempted to travel because of a photo seen on a social network and $82.69 \%$ of them visited a tourist area after viewing a photo posted on a social network. This proves that a well thought out post can make the difference between intention and action, travel agencies having to plan very well their social media communication strategy. 


\section{REFERENCES}

Erol G., Ülkü A. (2019). Social Media and Tourism. Chapter 10 in Current issues in Tourism and Hospitality Management, Strategic Researches Academy (SRA), ISBN: 978-605-69709-1-7

Gupta H., Singh S., Sinha P. (2017). Multimedia tool as a predictor for social media advertising- a YouTube way. Multimed Tools Appl 76:18557-18568, doi 10.1007/s11042-016-4249-6

Nikjoo A.H., Ketabi M. (2015). The role of push and pull factors in the way tourists choose their destination. An International Journal of Tourism and Hospitality Research, 4(26), 588-597

Roberts M., Callahan L., O'Leary C. (2017). Social media: A path to health literacy. Information Services \& Use 37 (2017) 177-187, doi 10.3233/ISU-170836

Shirky C. (2011). The Political Power of Social Media: Technology, the Public Sphere, and Political Change, Foreign Affairs, Vol. 90, No. 1 (JANUARY/FEBRUARY 2011), pp. 28-41

Sârbu R., Alecu F., Dina R. (2018). Social media advertising trends in tourism. Amfiteatru Economic, 20 (Special No. 12), 1016-1028, doi: 10.24818/EA/2018/S12/1016

Varga E.I. (2018). The importance of social media. Annals of the „Constantin Brâncuşi” University of Târgu Jiu, Economy Series, Issue 6/2018, 80-91

Živković R., Gajić J., Brdar I. (2014). The impact of social media on tourism. SINTEZA 2014 E-Business in tourism and hospitality industry, 758-761, doi: 10.15308/SInteZa-2014-758-761

Digital 2020 October Global Statshot Report - https://datareportal.com/reports/digital-2020october-global-statshot

http://statistici.insse.ro:8077/tempo-online/\#/pages/tables/insse-table

www.statista.com

www.instagram.com

www.facebook.ro

https://www.turismmarket.com/instagram-in-topul-retelelor-de-socializare-in-turism

https://sproutsocial.com/insights/social-media-statistics/

http://www.facebrands.ro

https://www.zelist.ro 